\title{
Modification of Carbon Nanotube for Synthesis of Titania Nanotube (Tint)-Carbon Nanotube (Cnt) Composite
}

\author{
Desi Heltina $a^{a, b}$, Praswasti PDK. Wulan ${ }^{a}$, Slameta \\ ${ }^{a}$ Department of Chemical Engineering, Faculty of Engineering, Universitas Indonesia, Depok. \\ ${ }^{b}$ Chemical Engineering, Faculty of Engineering, Universitas Riau, Riau. \\ Email: slamet@che.ui.ac.id
}

\begin{abstract}
Carbon nanotube (CNT) is a material widely chosen for object of research in nano technology. Apart from its good absorbent property, CNT also has a unique structure, superior mechanic and electric properties and its high strength. The property of CNT above is to be expected to improve performance of Titania nanotube (TiNT) composite. Properties of pure CNT are hydrophobic at the surface and low dispersion stability. To improve dispersability of CNT then modification need to be modified. Adding Cetyl trimethyl ammonium bromide (CTAB) surfactant on CNT is a way to increase dispersion stability of TiNT-CNT. The objective of the research was to study influence of adding of Cetyl trimethyl ammonium bromide (CTAB) surfactant to synthesis of TiNT-CNT composite in degrading phenol compound. Pure CNT was added with CTAB surfactant in liquid, then was sonificated and dried. Surfactant Cetyl trimethyl ammonium bromide (CTAB) added CNT then composited with TiNT. Phenol degradation then tested by using TiNT-CNT (CTAB) in reactor for 4.5 hours. Then sample was characterized by employing Field Emission Scanning Electron Microscopy (FESEM), X-ray Diffraction (XRD), Fourier Transform Infra-Red (FTIR) and UV-vis Spectroscopy. The result of experiments from FESEM characterization showed forming of TiNTCNT composites morphology. From X-ray Diffraction (XRD) characterization showed crystal formed on TiNT-CNT only of anatase crystal. Degradation of TiNT-NT composite (CTAB) to phenol was also studied.
\end{abstract}

Keywords: Titania nanotube (TiNT)-Carbon nanotube (CNT) composite; Surfactant; Cetyl trimethyl ammonium bromide (CTAB); Phenol

\section{INTRODUCTION}

Photocatalysis process was occurred when photocatalyst and pollutant in contact. Most of photocatalyst semiconductor including $\mathrm{TiO}_{2}$ has low adsorption, so that process of contact between photocatalyst and pollutant is not maximal and rate of recombination of electron is high with low utility [1], [2]. To overcome these drawbacks, photocatalysis by semiconductor photocatalyst need to be supported by an adsorbent as buffer [3]. In this case, $\mathrm{TiO}_{2}$ samples is doped with non-metal elements, such as nitrogen, sulphur dan carbon to increase photocatalyst activity of visible light [4], [5]. Therefore, development to increase performance of photocatalyst $\mathrm{TiO}_{2}$ is still becomes an interesting topic. By mixing photocatalyst and adsorbent, it is expected the contact between photocatalyst with pollutant become more effective. Further, used adsorbent is not require to be regenerated 
because pollutant sticked on absorbent will degraded in situ by photo-catalyst so that saturation of absorbent can be avoided [6], [7].

Based on the previous research, it was known that the use of adsorbent as buffer can increase the rate of photo-degradation for various pollutants [6]. Used adsorbent was porous media, so that photocatalyst could get into pores or sticked on absorbent surface.

Combination of photocatalysis-absorption is mixing of two processes with two materials which are photocatalyst (TiNT) and adsorbent (CNT) materials to produce composite material for various applications, one of them are pollutant material treatment. Producing of composite of adsorbent compound with photocatalyst make use some of additive chemical compound or modifier. Addition of the compound has an objective to increase the interaction between Titania and Carbon. Some interaction occurred regarding the addition, in some cases such as hydrophobic, interaction of $\pi-\pi$, interaction of electron-donor-acceptor (EDA), electrostatic interaction and hydrogen linking [8].

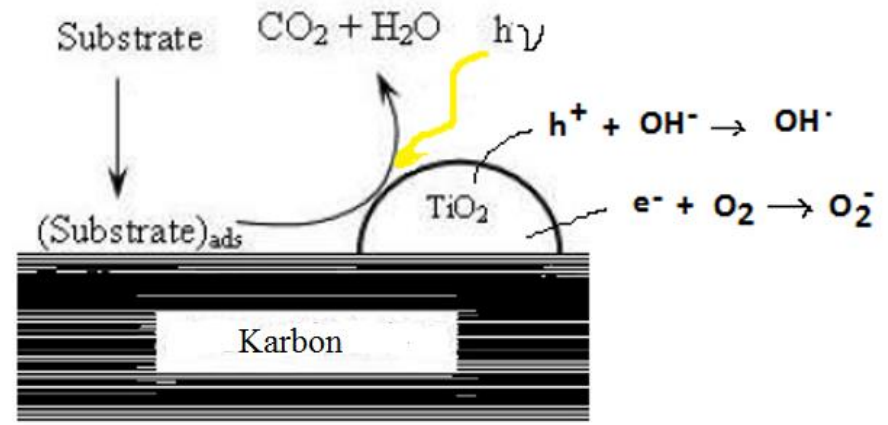

Figure 1.1 Illustration of combination of absorption-photocatalysis process

The composites consist of filler and matrix which produce bonding and acquired mechanical properties different from basic properties of each constituent component because interface between two constituent components. Interface is a surface built from bonding of matrix and filler for load transmitting. The interface could be inter atomic bonding, reaction inter matrix also can be strengthening of layer. The shape of composite morphology is based on surface modifications which are core cell, parallel and random.

The formation of composite can viewed from some approach, in which by functional group bonding and electron charge from the substance. The functional groups and electron charge could be formed thru treatment. One of the treatments is by acid and surfactant treatment. Surfactant surface could prevent grain formation during phase transformation and stabilize very small particle and make easy dispersion [9].

Adding of surfactant showed many bonding formed by other than covalent bonding. Surfactants acts as linking agent of surface adsorption of CNT by interaction of $\pi-\pi$. Surfactant has molecular structure consisted of hydrophilic and hydrophobic group. Hydrophilic group could be dispersed well in the water and organic solute, while hydrophobic group will make bonding with CNT.

Cetyl trimethyl ammonium bromide (CTAB) is one of surfactant from cationic type which could be used for modifying of CNT surface. Modified CNT by adding of CTAB is expected to increase dispersion of solution in synthesis of composites TiNT-CNT process, so that the TiNT-CNT composite could be formed.

The research was started with adding of CTAB in CNT. TiNT was synthesized from $\mathrm{TiO}_{2} \mathrm{P} 25$ and then continues to synthesis process of TiNT -CNT (CTAB) composites. 
The general objective of the research was to acquire TiNT -CNT (CTAB) composite which has good performance of photocatalyst activity in degrading phenol.

In this research also developed a material engineering by combining adsorption photocatalyst process on composites TiNT - CNT to acquire optimum parameter and condition in increasing of performance efficiency of composite material. Material engineering on this TiNT-CNT (CTAB) composite will be tested for effectivity of performance to eliminate phenol.

\section{Methodology}

CNT for the research was MWCNT type purchased from Dong Yang (HK) Int'I Group Limited of diameter $10-30 \mathrm{~nm}$, length of $5-15 \mu \mathrm{m}$, and purity of $99 \%$, Cetyl trimethyl ammonium bromide (CTAB), $\mathrm{TiO}_{2}(\mathrm{P} 25), \mathrm{NaOH}, \mathrm{HCl}$, and aquades.

\subsection{Synthesis of Titania nanotube (TiNT)}

TiNT was synthesized by using hydrothermal process from $\mathrm{TiO}_{2}$ (P25) added with $\mathrm{NaOH} 10 \mathrm{M}$ in autoclave in temperature of $130^{\circ} \mathrm{C}$ with stirring speed of $600 \mathrm{rpm}$ for 6 hour, solution then rinsed with $\mathrm{HCl}$ and rinsed again by aquades until neutral $\mathrm{pH}$. Then sample was dried.

\subsection{Adding of surfactant Cetyl trimethyl ammonium bromide (CTAB) on Carbon nanotube}

$1 \mathrm{~g}$ of carbon nanotube (CNT) was added with CTAB surfactant of $0.5 \mathrm{~g}$ in $100 \mathrm{ml}$ aquades. Solution was then sonicated for 1 hour. Then solution was dried.

\subsection{Synthesis of Titania Nanotube (TiNT)-Carbon Nanotube (CNT) Composite}

$0.015 \mathrm{~g}$ CNT surfactant (CTAB) was added into $1 \mathrm{~g}$ of TiNT, the stirred by using magnetic stirrer for 3 hours. Solution then dried in temperature of $80^{\circ} \mathrm{C}$, then mashed by pestle. Sample was then calsinated with in temperature of $400^{\circ} \mathrm{C}$ for 2 hour.

\subsection{Performance test of TiNT-CNT composites using phenol compound}

$0.3 \mathrm{~g}$ composite sample TiNT-CNT was put into $300 \mathrm{ml}$ of phenol liquid $10 \mathrm{ppm}$. The experiment was conducted for 270 minutes (4.5 hour), in which first 30 minutes was conducted without light (light off) and next 240 minutes the photodegradation using UV lamp as photon source (light on) was conducted. Photocatalyst used for the process was 0.3 grams powder and continuously stirred during experiment in order to make photocatalyst particles and phenol distributed evenly in sample solution. Quantitative result of degrade phenol was acquired by using spectrometer in accordance with procedure on SNI 06-6989.21-2004.

\subsection{Characteristic}

Sample was characterized by using FESEM, XRD, FT-IR and UV-vis spectroscopy.

\section{Results and Analysis}

In Figure 3.1 (a-c) showed the morphology of CNT, TiNT and TiNT-CNT (CTAB) composite in $\mathrm{pH}$ 3. Figure $3.1(a-b)$ also showed that morphology of CNT CTAB and TiNT was in tube shape. Figure $1 \mathrm{c}$ is morphology of TiNT-CNT (CTAB) composite and it showed that CNT CTAB was evenly distributed on TiNT matrix. Tube shape of TiNT and CNT can be seen formed random link. The link of tube formed composited so that adsorption-photocatalysis process able to perform synergy in conducting each task. This was supported by FT-IR result. 

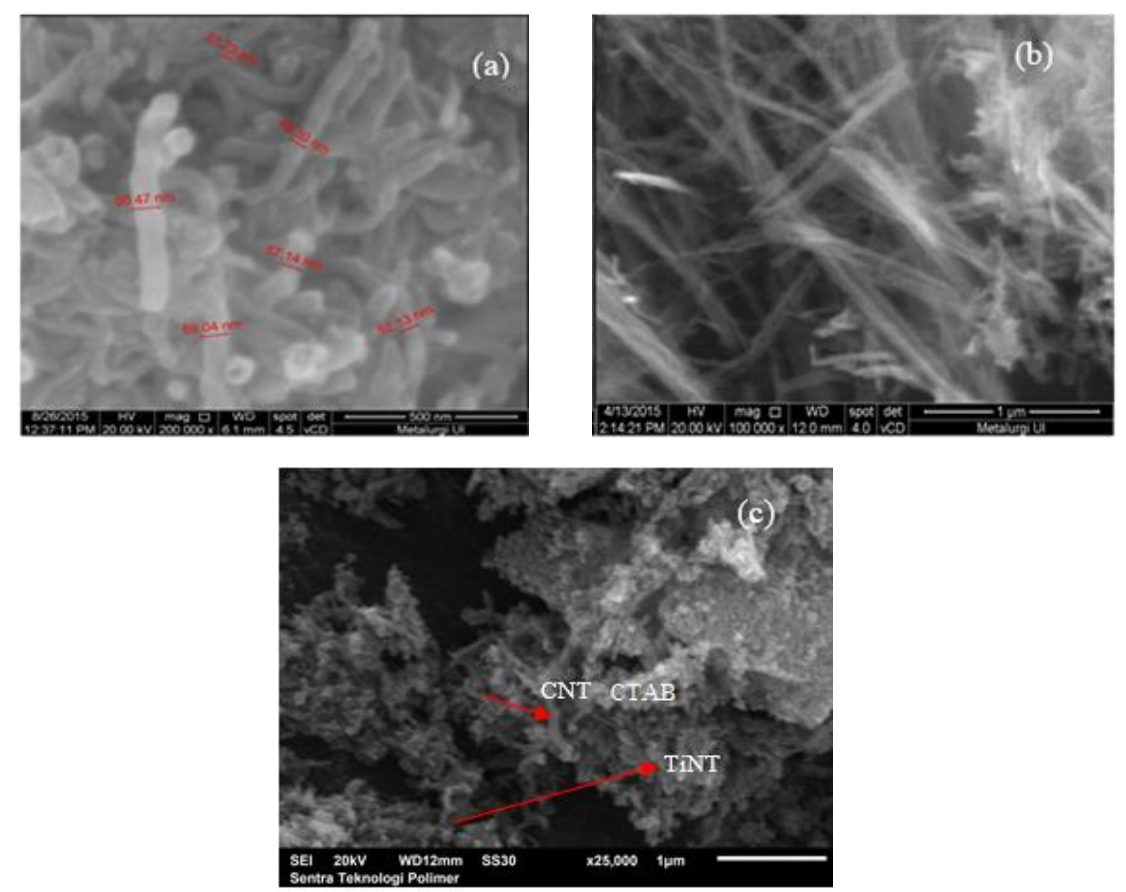

Figure 3.1 FESEM (a) CNT CTAB (b) TiNT (c) TiNT-CNT (CTAB) composite in pH 3

Figure 3.2 depicted photo-catalyst of TiNT-CNT composite have peak on of $2 \theta$ : $25.28^{\circ}, 37.87^{\circ}, 48.10^{\circ}, 54.04^{\circ}$, and anatase $55.08^{\circ}$, This showed the existence of anatase crystal phase (JCPDS no. 21-1272). Photocatalytically, anatase structure showed better activity of reactivity compare with rutile structure [10]. Anatase structure is form frequently used because having bigger powder surface area and smaller particle compare with rutile structure and this structure occured in range of heating temperature of decomposition of titanium compound $\left(400^{\circ} \mathrm{C}-650^{\circ} \mathrm{C}\right)$.

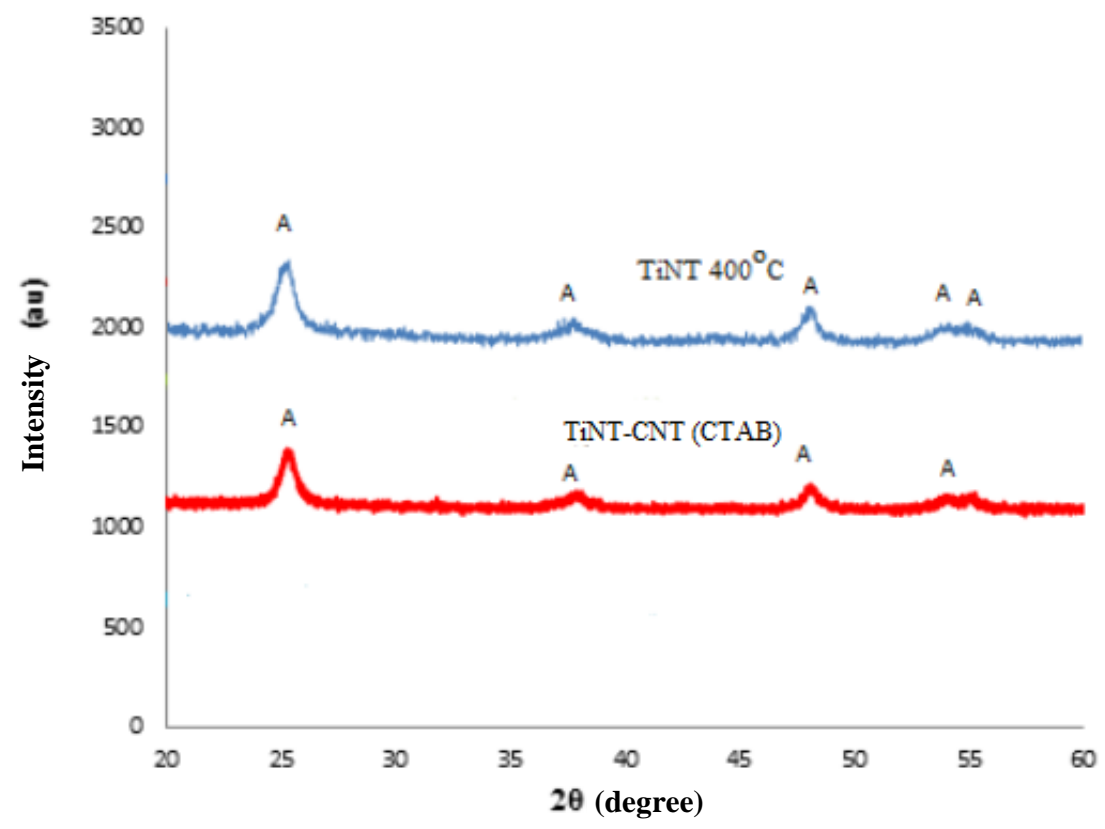

Figure 3.2 Analysis result of XRD TiNT and TiNT-CNT(CTAB) composite $\mathrm{pH} 3$ 
JEMMME, Vol.1, No. 1, November 2016

ISSN 2541-6332

e-ISSN 2548-4281

Table 3.1 Size of Anatase Crystal

\begin{tabular}{cc}
\hline Catalyst & Size of anatase crystal $(\mathrm{nm})$ \\
\hline TiNT $400^{\circ} \mathrm{C}$ & 7.4 \\
\hline TiNT-CNT $(\mathrm{CTAB})$ & 9.8 \\
\hline
\end{tabular}

Table 3.1 showed the size of anatase crystal $(\mathrm{nm})$ of TiNT catalyst and TiNT-CNT (CTAB) composite. TiNT and TNT-CNT( CTAB) composite has crystal size of 7,4 nm and $9,8 \mathrm{~nm}$ consecutively. The shape of anatase crystal showed low level of catalyst reactivity under $10 \mathrm{~nm}$. So that it much influenced the performance of catalyst in degrading phenol. It was showed in Figure 3.4 in which percentage of catalyst performance still low.

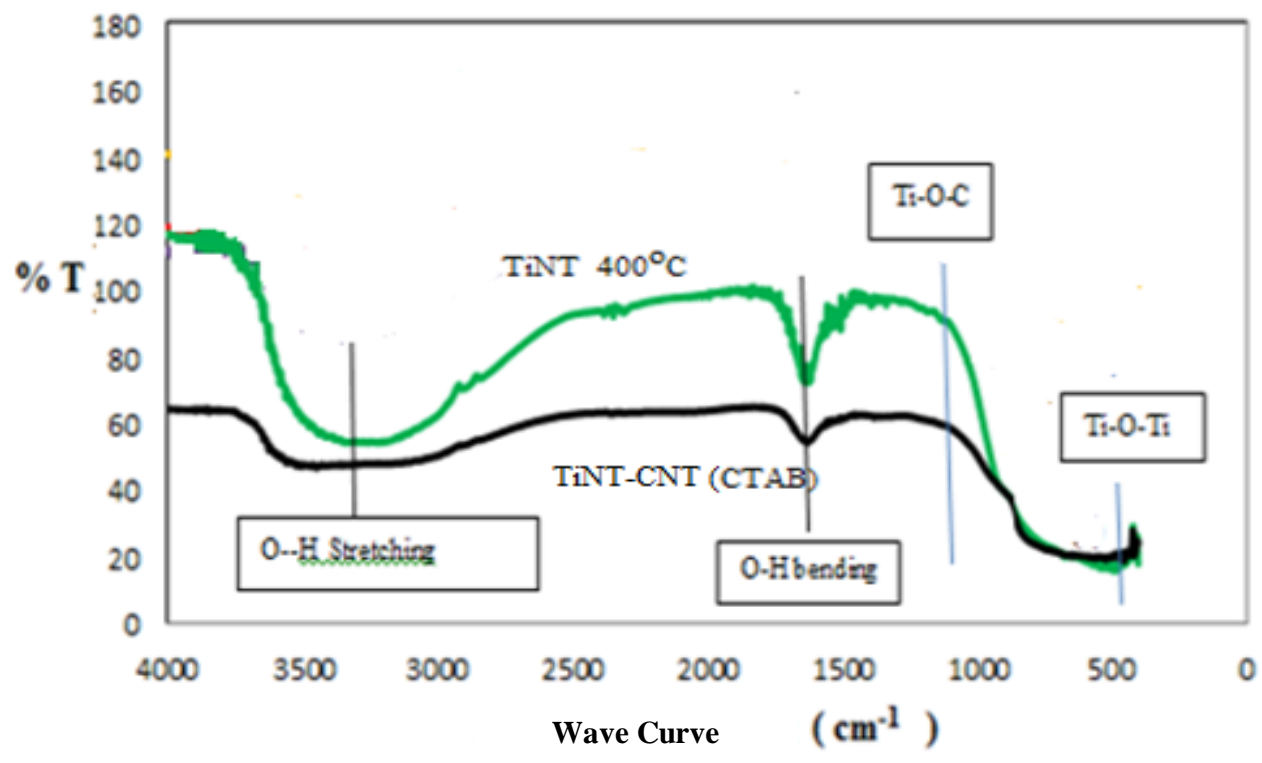

Figure 3.3 Results of FT-IR TiNT and TiNT-CNT (CTAB) composite

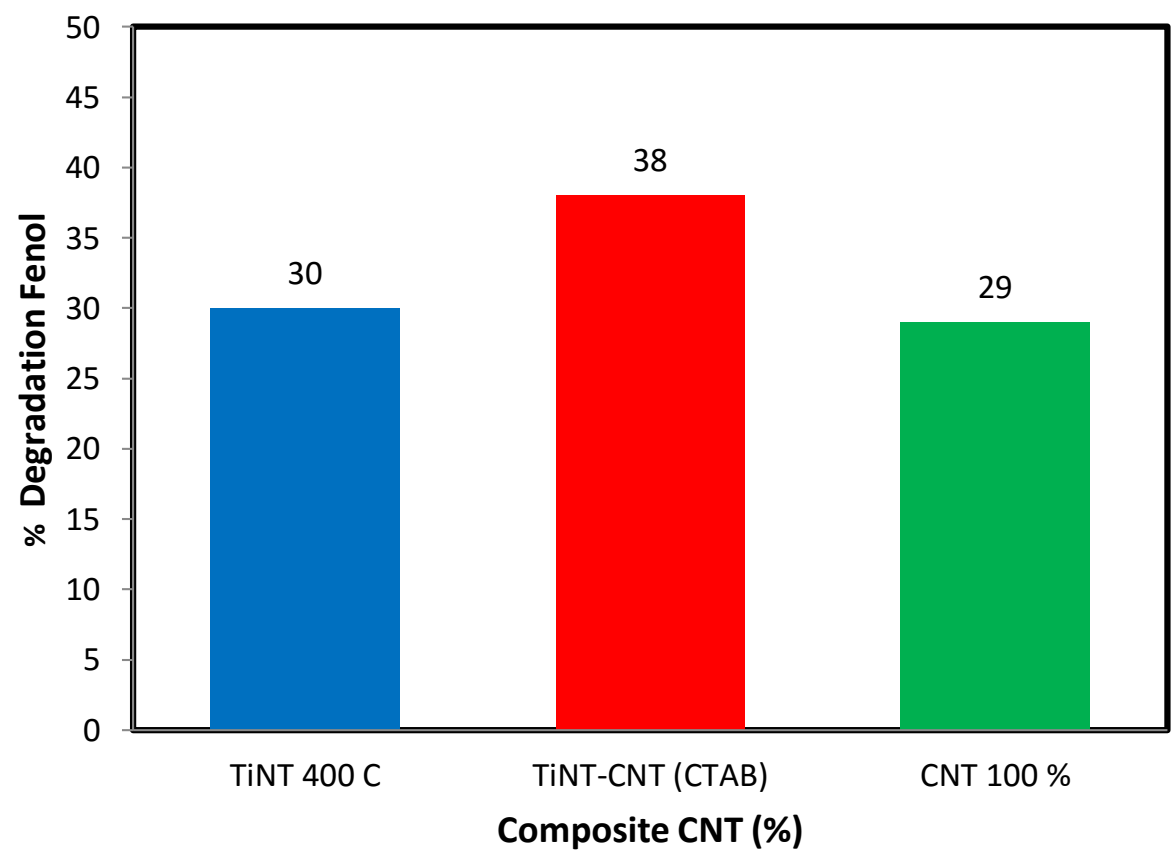

Figure 3.4 Effectifity of performance of TiNT-CNT(CTAB) composite to phenol degradation

JEMMME | Journal of Energy, Mechanical, Material, and Manufacturing Engineering 
The peak of available function groups in photocatalyst can be determined by FT-IR analysis as shown in Figure 3 below. Transmittance peaks showed in 420 and $840 \mathrm{~cm}^{-1}$ depict Ti-O-Ti stretching vibrations bond of $\mathrm{TiO}_{2}$ crystal [11]. Carboxyl group which be marked by $\mathrm{OH}$ bond in carboxylate acid and spread to spectrum of $3400-2400 \mathrm{~cm}^{-1}$ identified as $\mathrm{O}-\mathrm{H}$ stretching bond of $\mathrm{OH}$ bond to $\mathrm{Ti}$ atom [12]. Meanwhile, for all photocatalyst, the peak was around in $1560 \mathrm{~cm}^{-1}$ which constitute bending bond of surface containing hydroxyl group (surface which adsorb water molecules).

Figure 3.3 showed the performance of photocatalyst in degrading phenol from TiNT material, TiNT-CNT (CTAB) composite and CNT. Percentage of highest degrading phenol of performance of TiNT-CNT (CTAB) composite was $38 \%$ higher than the one of individual performance of TiNT dan CNT CTAB. This showed that the objective of compositing of TiNT and CNT (CTAB) could be achieved in order to increase the effectivity of material performance in degrading phenol. But, it needs also considering other factors which have influence on degradation activity such as crystalinity, morphology and function group.

\section{CONCLUSION}

TiNT-CNT (CTAB) composite has been successfully synthesized by using Cetyl trimethyl ammonium bromide (CTAB) added CNT. Effektivity of performance of TiNT-CNT (CTAB) composite was influenced by morphology, function group and crystalinity. TiNTCNT (CTAB) composite able to degrading phenol for $38 \%$ (in 4,5 hour of experimental result).

\section{REFERENCES}

[1] Chen, X., Mao, S,S. Titanium Dioxide Nanomaterials: Synthesis, Properties, Modifications and Applications. Journal of Chemical Reviews. 2007; 107: 2891-2959.

[2] Burda, C., Chen, X., Narayanan, R., El-Sayed, M, A. Chemistry and properties of nanocrystals of different shapes. Journal of Chemical Reviews. 2005; 105, (4): 10251102.

[3] El-Maazawi, M., Finken, A.N., Nair, A.B., Grassian, A, V. Adsorption and photocatalytic Oxidation of Acetone on $\mathrm{TiO}_{2}$ : An in Situ Transmission FT-IR Study. Journal of Catalysis. 2000; 191, (1): 138-146.

[4] Ohno, T., Akiyoshi, M.,Umebayashi, T., Asai, K., Mitsui, T., Matsumura, M. Preparation of S-doped $\mathrm{TiO}_{2}$ photocatalysts and their photocatalytic activities under visible light. Journal of Applied Catalysis A: General. 2004; 265, (1): 115-121.

[5] Nakamura, S,S., R., Abe, S. Visible-light sensitization of $\mathrm{TiO}_{2}$ photocatalysts by wetmethod N doping. Journal of Applied Catalysis A: General. 2005; 284, (1-2): 131137.

[6] Torimoto, T., Ito, S., Kuwabata, S., dan Yoneyama, H. Effects of Adsorbents Used as Supports for $\mathrm{TiO}_{2}$ Loading on Photocatalytic Degradation of Propyzamide. Journal of Environment Science Technology. 2009; 30: 275-1281.

[7] Slamet, Ibadurrohman, M. Purifikasi Udara dari Polutan Asap Rokok Menggunakan Kombinasi Proses Adsorpsi - Fotokatalisis dengan Nanokomposit $\mathrm{TiO}_{2}-$ Karbon Aktif. Jurnal Riset Industri. 2009; 3, (1): 1-85.

[8] Liu, X., Wang, M., Zhang, S., Pan, B. Application potential of carbon nanotubes in water treatment: A review. Journal of Environmental Sciences. 2013; 25: 1263-1280.

[9] Bouazza, N., Ouzzine, M., Lillo-Ródenas, M. A., Eder, D., Linares-Solano, A. $\mathrm{TiO}_{2}$ nanotubes and $\mathrm{CNT}-\mathrm{TiO}_{2}$ hybrid materials for the photocatalytic oxidation of propene at low concentration. Journal of Applied Catalysis B: Environmental. 2009; 92, (3-4): 377- 383 .

[10] Su, C., Hong, Y, B., Tseng, M, C. Sol-gel Preparation and Photocatalysis of Titanium Dioxide. Journal of Catalysis Today. 2004; 96: 119-26. 
[11]Liang, L., Yulin, Y., Xinrong L., Ruiqing F., Yan S., Shuo L.,et al. A Direct Synthesis of $\mathrm{B}$-doped $\mathrm{TiO}_{2}$ and Its Photocatalytic Performance on Degradation of RhB. Appl, Surf, Sci. 2013: 36-40.

[12]Pang, Y, L., Abdullah, A, Z. Effect of Carbon and Nitrogen Co-Doping on Characterizatics and Sonocatalytic Activity of $\mathrm{TiO}_{2}$ Nanotube Catalyst for Degradation of Rhodamine B in Water. Chem, Eng, J. 2013: 129-138. 